\title{
Interregional variations in measures of health from the Health and Lifestyle Survey and their relation with indicators of health care need in England
}

\author{
Nicholas Mays, Susan Chinn, Kit Mui Ho
}

\begin{abstract}
Study objective-The aim was to assess the extent to which a range of routinely available need indicators which have been suggested for use in NHS spatial resource allocation formulas were associated geographically in England with the different dimensions of population health status collected in the 1985/86 Health and Lifestyle Survey (HLS).
\end{abstract}

Design-Regional health authorities were ranked according to each of the HLS health variables which varied significantly between authorities. The HLS health variables were regressed on a selection from the range of routinely available morbidity and socioeconomic indicators available from the 1981 census. The potential need indicators were also regressed on the health variables.

Setting-The analyses were undertaken at individual level and at regional health authority level in England.

Subjects-The study comprised the English component of the HLS random sample representative of the population in private households in Great Britain.

Main results-The different HLS health variables did not yield consistent regional health authority rankings. Among the variables, forced expiratory volume in one second $\left(F^{2} V_{1}\right)$ and self assessed health appeared to be associated with most of the other health and need variables except longstanding illness. Longstanding illness was not strongly associated with any of the other HLS health variables but appeared to show some association with three deprivation indices constructed from the 1981 Census.

Conclusions-There may be a case for including a measure of chronic ill health in the new NHS system of capitated finance in addition to the all cause standardised mortality ratio which is used currently as a measure of need for health care.

Department of Public Health Medicine, United Medical and

Dental Schools of Guy's and St

Thomas's Hospitals,

Thomas's Hospitals,

London SE1 7EH,

United Kingdom

N Mays

S Chinn

K M Ho

Correspondence to: Dr Mays

Accepted for publication February 199 boundary patient flows and medical student teaching costs. The formula used mortality rates in the form of standardised mortality ratios to account for the variations in need, defined in terms of relative morbidity or unhealthiness, which remained after the age/sex structure of the population of each region had been taken into account. Similar fomulas operated in the NHS in the other constituent parts of the United Kingdom. Each NHS region used its own variant of the national formula, adjusted for local circumstances, to influence resource allocation between its district health authorities.

Between April 1986 and July 1988 the national RAWP process in England was the subject of a review $^{2}$ by a group appointed by the NHS Management Board (since January 1989, known as the NHS Management Executive). On the basis of an analysis of the relationship between inpatient utilisation and population health and socioeconomic features, ${ }^{3}$ the RAWP review recommended that the standardised mortality ratio weighting in the formula be reduced from 1.0 to 0.44 and that a new allowance for "social factors" in the form of a deprivation index, such as the Jarman 8 underprivileged area (UPA) score, should be included. ${ }^{4}$

In January 1989, the Conservative government published its white paper on the future of the NHS, "Working for Patients". 5 The white paper announced that from April 1990, the RAWP formula would be abolished. Yet the white paper also made it clear that the underlying principle of RAWP - an equitable geographical distribution of financial resources in relation to need-would be retained. From 1990/91, the Government simplified the former RAWP process by ending the retrospective adjustment of health authority resource "targets" for cross boundary flows and by eliminating the distinction between "targets" and actual allocations. Instead, over a two year period, regional health authorities will move to a system of funding on the basis of their resident populations, weighted to reflect the health and demographic characteristics of the population and the relative costs of providing services in different parts of the country. It is proposed that standardised mortality ratios will continue to be used as a morbidity measure, but in the form of all cause ratios under 75 years, with a weighting of $0 \cdot 5 .^{6}$ There has been no mention of an allowance for needs associated with "social factors" in the new capitation formula. The Department of Health has admitted that the proposals of the RAWP review were "over precise" the problems which have subsequently become apparent in the analysis on which they were based. $^{7}$ 
The abolition of RAWP, followed by its immediate reintroduction in a modified form, has ensured that the question of which need indicators to use in NHS resource allocation continues to be a subject of debate. The adequacy of mortality data as a proxy measure of population morbidity and thereby of need has been criticised ever since RAWP was first implemented in 1977/ 78. ${ }^{8-13}$ Despite these criticisms several studies have produced results which support the use of mortality data, both as a morbidity indicator ${ }^{14} 15$ and as an indicator of social deprivation likely to be associated with additional health resource needs. ${ }^{15-18}$

Overall, the research suggests that mortality, in the form of standardised mortality ratios, is a reasonable proxy for needs associated with population morbidity. The existence of needs associated with social deprivation which may not be directly reflected in ill health (eg, the presence of ethnic minorities), and the adequacy of standardised mortality ratios as indicators of these needs, remains more controversial. Although the possibility of there being additional needs generated by certain aspects of social deprivation is discussed below, the analysis in this paper concentrates on need as a function of health status and morbidity in a population.

Previous studies of mortality, morbidity, and need have tended to suffer from their reliance on the limited range of routinely available morbidity data that exists in the United Kingdom, such as the General Household Survey or the decennial census. In the absence of regular population health surveys in the United Kingdom, it is difficult to know which of the need indicators currently used in NHS resource allocation, or favoured for inclusion by critics of the prevailing formula, or used to validate other indicators such as standardised mortality ratios, are themselves valid measures of needs associated with ill health. The Health and Lifestyle Survey carried out in $1984 / 85$ offers a unique and relatively up to date, national morbidity database with which to assess the extent to which standardised mortality ratios, and other routine need variables which have been proposed for use in regional or subregional resource allocation to health authorities, are good indicators of those needs likely to be reflected in the relative healthiness or unhealthiness of different populations. ${ }^{1920}$

The Health and Lifestyle Survey comprises a large (9003 adults) random sample representative of the population in private households in Great Britain and includes a wide range of different measures of health. Data are available on physiological markers of health status (blood pressure and respiratory function), body measurements (height, weight, girth, etc), cognitive function, and psychological well being, as well as a range of subjective and self reported health variables (symptoms, self assessed health, longstanding illness or disability, self reported chronic complaints, etc). It is possible, therefore, to use the Health and Lifestyle Survey to assess how well mortality data and other possible need indicators perform as predictors of each of the different dimensions of population health included in the survey; and to use it also to contribute to a better understanding of the appropriate need variables to be included in the different NHS geographical resource allocation formulas used in England, Wales, Scotland and Northern Ireland.

The analysis which follows explores the interrelation between the physical, physiological, self reported, and subjective measures of health status recorded in the Health and Lifestyle Survey at the level of individual respondents and at regional level in England; secondly, it provides rankings for each regional health authority on each of the dimensions of ill health from the Health and Lifestyle Survey; and thirdly, it describes the degree of association between the Health and Lifestyle Survey variables and a range of routinely available need indicators such as standardised mortality ratios, permanent sickness, Jarman 8 UPA score, ${ }^{4}$ etc, at regional level. The correlations between the need indicators at regional level are also reported. The objectives are thus twofold: (1) to assess the extent to which a range of routinely available need indicators is associated geographically with measures of population health status; and (2) to assess the extent to which self reported and subjective reports of health from interviews correlate geographically and at an individual level with physiological and physical measurements such as blood pressure and body weight.

\section{Methods}

A copy of the Health and Lifestyle Survey data file was supplied on magnetic tape by the ESRC data archive at the University of Exeter. Data for 169 parliamentary constituencies in England were used in the analysis. Wales and Scotland were omitted.

ALLOCATION OF CONSTITUENCIES AND WARDS TO REGIONAL HEALTH AUTHORITIES

Colleagues at the University of York who were also working on the Health and Lifestyle Survey data (Dr Roy Carr-Hill and Mr Russell Slack) provided a constituency to regional health authority conversion. This was checked using a 1981 ward name to ward code list for English counties supplied by OPCS ${ }^{\mathrm{a}}$ Customer Services Division, combined with a file provided by the ESRC data archive which enabled ward codes to be allocated to regional health authorities.

RESPONSE RATE ON THE HEALTH STATUS VARIABLES AND SAMPLING BIAS

The Health and Lifestyle Survey data file includes a range of measures of self reported health obtained by interview and objective measurements carried out by a specially trained nurse. The response rate for England was $72.4^{\circ}$ o for the self assessed measures and $60.0 \%$ for the objective measurements, with considerable variation between standard regions. ${ }^{19}$ The regional response to the survey ranged from a $64.2 \%$ response rate to the interviews and $51.0 \%$ to the measurements in Greater London up to $79.6 \%$ for the interviews in the Northern Region and $66.7 \%$ for the measurements in East Anglia. ${ }^{19}$ The objective measures appear more likely to be

${ }^{a}$ Office of Population Censuses and Surveys 
subject to response bias than the subjective reporting. In this secondary analysis it was not possible to allocate the entire original survey sample to regional health authorities. Thus it was only possible to examine the response to the individual measures of those who agreed to be interviewed. Of those responding to interview, over $99 \%$ in each NHS region had completed the self assessed health measures and a minimum of $70.6 \%$ and maximum of $86.8 \%$ had completed one or more of the objective measures (table I).

CHOICE OF HEALTH VARIABLES FOR THE ANALYSIS Measures of psychological and cognitive functioning from the Health and Lifestyle Survey were not included in this study. Of the remaining health variables, only those with significant interregional variation were included in the analysis, on the basis that variables which did not vary significantly were unlikely to show consistent relations with one another at regional level. Details of the formulation of the health variables are given in the appendix.

A file was created to include all those health variables which showed significant interregional variation, to which were added data to construct a variety of conventional need indicators, namely, all cause, all age standardised mortality ratios calculated for 1984 and 1985 (the years of the Health and Lifestyle Survey), population estimates, and selected socioeconomic data from the 1981 census which could be used to compile regional health authority scores on three indices of social deprivation, the Jarman UPA score, ${ }^{4}$ Townsend's index of material deprivation, ${ }^{21}$ and the Department of the Environment (DoE) social index.

\section{Results}

SPATIAL VARIATION IN THE HEALTH AND LIFESTYLE SURVEY HEALTH VARIABLES

Each of the physical measurements (ie, body mass index, forced expiratory volume in one second $\left(\mathrm{FEV}_{1}\right)$, and the three blood pressure measurements, systolic, diastolic, and mean arterial pressure) showed significant variation between regional health authorities $(p<0.001)$. There was also significant variation in these measurements between parliamentary constituencies, with the exception of body mass index. Turning to the subjective and self reported variables, not all the self reported illnesses showed significant interregional variation (see table II for those that did vary significantly). Self reported asthma, chronic bronchitis, other chest trouble, diabetes, stomach or other digestive disorder, liver trouble, heart trouble, lung cancer (only eight cases in total), other cancer, varicose veins, high blood pressure, stroke, migraine, and back

Table I Health and Lifestyle Survey: data availability for selected health variables in England

\begin{tabular}{|c|c|c|c|c|}
\hline & $\begin{array}{l}\text { Self assessed } \\
\text { health }\end{array}$ & $F E V_{1}$ & $B M I$ & $\begin{array}{l}\text { Blood } \\
\text { pressure }\end{array}$ \\
\hline Total number of respondents & 7548 & 5764 & 6167 & 6252 \\
\hline $\begin{array}{l}\text { As \% of those agreeing to } \\
\text { be interviewed }\end{array}$ & $99 \cdot 6$ & $76 \cdot 1$ & $81 \cdot 4$ & $82 \cdot 5$ \\
\hline $\begin{array}{l}\text { Range between NHS regions } \\
\text { in \% of those agreeing to } \\
\text { be interviewed }\end{array}$ & $99 \cdot 2-100 \cdot 0$ & $56 \cdot 2-83 \cdot 2$ & $76 \cdot 9-86 \cdot 1$ & $78 \cdot 0-86 \cdot 8$ \\
\hline
\end{tabular}

trouble all showed no significant $(p>0 \cdot 1)$ variation between regional health authorities. The variation in reports of at least one of the 18 self reported illnesses just failed to attain significance at the $5 \%$ level.

RELATIONS OF SELF ASSESSED HEALTH TO OTHER HEALTH VARIABLES FROM THE HEALTH AND LIFESTYLE SURVEY AT THE INDIVIDUAL LEVEL

The relations between the self assessed health measure and the range of self reported illness variables were explored at an individual level. Self assessed health status was related independently to 14 of the 18 specified types of illness after allowing for age and sex. Allowing for all the 18 specified illnesses, there remained a significant relation between self assessed health and the prevalence of a longstanding illness, disability, or infirmity and a significant variation between regional health authorities. Self assessed health was also strongly negatively related to $\mathrm{FEV}_{1}$ and positively to body mass index, but not to systolic or diastolic blood pressure. The significant relations between self assessed health and stroke, back trouble, and epilepsy ceased to be significant when longstanding illness, disability or infirmity, and the physical measurements were taken into account. The strongest relations with self assessed health at the individual level were with longstanding illness, $\mathrm{FEV}_{1}$ (negatively), heart trouble, and severe depression or other nervous illness.

RANKING OF HEALTH VARIABLES FROM THE HEALTH AND LIFESTYLE SURVEY AT REGIONAL LEVEL

Table II gives the values and regional rankings for each of the self reported survey health variables which showed significant interregional variation in the preliminary analyses. The rankings indicate that the three more general self reported measures of self assessed health, recent symptoms, and longstanding illness had similar rankings in most regions, although this does not apply to North East Thames and South East Thames. The more specific self reported prevalence variables show a more inconsistent set of regional rankings. For example, East Anglia is third "best" (ie, low prevalence) for severe depression and other nervous illness, but thirteenth for epilepsy or fits. The physical measurements show a moderate degree of consistency in their regional rankings (table III). The comparison of the regional rankings for the generic self reported variables and for the physical measurements reveals that for some regions, notably Northern at the "poor" end of the health spectrum and South West Thames at the "good" end, there is a strongly consistent set of rankings (table III). This also holds when the specific self reported prevalences are included (table II). However, in other regions, for example, South East Thames, Trent, and Oxford, the rankings on variables are inconsistent.

RANKINGS OF ROUTINELY AVAILABLE “NEED" INDICATORS AND HEALTH AND LIFESTYLE SURVEY VARIABLES

The 14 NHS regions were also ranked according to their scores on a selected range of routinely available measures, which have been suggested as possible indicators of the need for health care 
resources (table IV). There was a high degree of consistency between variables in their rankings, particularly for all cause standardised mortality ratios, permanent and temporary sickness rates from the 1981 census, and the percentage in social classes IV and V. The three indices of deprivation (Jarman 8, Townsend, and DoE) behaved somewhat differently, since they tended to show "worse" (more deprived) scores for the Thames regions, particularly North East Thames and South East Thames, than standardised mortality ratios and the sickness measures.

The comparison of regional health authority rankings on the routine "need" indicators and on the Health and Lifestyle Survey self reported health variables and physical measurements shows that for a minority of regions the rankings are strikingly similar. For example, Northern Region and South West Thames appear as consistently "poor" and "good" respectively, in relative terms, across the entire range of variables. In contrast, North East Thames is ranked as the best region on self assessed health and symptoms, but thirteenth out of 14 on deprivation according to the Jarman 8 UPA score and DoE social index.

CORRELATIONS BETWEEN HEALTH VARIABLES FROM THE HEALTH AND LIFESTYLE SURVEY AT REGIONAL LEVEL

Self assessed health was most highly correlated with number of symptoms $(r=0.59)$, followed by piles $(r=0.52)$ and self reported depression $(r=0.52)$ (table IV). Number of symptoms in the last month was most highly correlated with self

Table II Regional prevalences of self reported health variables from Health and Lifestyle Survey (adjusted to males aged 18 to 24 years) and rankings ${ }^{\mathrm{a}}$

\begin{tabular}{|c|c|c|c|c|c|c|c|c|c|c|c|c|c|c|}
\hline \multirow[b]{2}{*}{$\begin{array}{l}\text { Region } \\
\text { Northern } \\
\text { Yorkshire } \\
\text { Trent } \\
\text { E Anglia } \\
\text { NW Thames } \\
\text { NE Thames } \\
\text { SE Thames } \\
\text { SW Thames } \\
\text { Wessex } \\
\text { Oxford } \\
\text { South Western } \\
\text { W Midlands } \\
\text { Mersey } \\
\text { North Western }\end{array}$} & \multicolumn{2}{|c|}{$\begin{array}{l}\text { Self assessed } \\
\text { health } \\
(\% \text { fair } / \text { poor })\end{array}$} & \multicolumn{2}{|c|}{$\begin{array}{l}\text { Number of } \\
\text { symptoms in } \\
\text { previous month } \\
\text { (Geometric mean) }\end{array}$} & \multicolumn{2}{|c|}{$\begin{array}{l}\text { Longstanding } \\
\text { illness } \mid \\
\text { disability } \mid \\
\text { infirmity } \\
\left(\begin{array}{c}0 \\
o\end{array}\right)\end{array}$} & \multicolumn{2}{|c|}{$\begin{array}{l}\text { Piles } / \\
\text { haemorrhoids } \\
(0 ; 0)\end{array}$} & \multicolumn{2}{|c|}{$\begin{array}{l}\text { Rheumatic } \\
\text { disorder } \mid \\
\text { arthritis } \\
\left(\begin{array}{c}0 \\
(0)\end{array}\right.\end{array}$} & \multicolumn{2}{|c|}{$\begin{array}{l}\text { Severe depression/ } \\
\text { other nervous } \\
\text { illness } \\
\left(\begin{array}{c}0 \\
0\end{array}\right)\end{array}$} & \multicolumn{2}{|c|}{$\begin{array}{l}\text { Epilepsy/ } \\
\text { fits } \\
\left({ }^{\circ}{ }_{0}\right)\end{array}$} \\
\hline & $\begin{array}{l}34 \cdot 8 \\
33 \cdot 6 \\
31 \cdot 6 \\
27 \cdot 7 \\
30 \cdot 1 \\
23 \cdot 2 \\
33 \cdot 5 \\
26 \cdot 7 \\
26 \cdot 3 \\
27 \cdot 1 \\
33 \cdot 2 \\
34 \cdot 8 \\
33 \cdot 2 \\
33 \cdot 8\end{array}$ & $\begin{array}{c}13= \\
11 \\
7 \\
5 \\
6 \\
1 \\
10 \\
3 \\
2 \\
4 \\
3= \\
13= \\
8= \\
12\end{array}$ & $\begin{array}{l}3.06 \\
2.66 \\
2 \cdot 77 \\
2 \cdot 74 \\
2.98 \\
2 \cdot 38 \\
2 \cdot 47 \\
2.47 \\
2 \cdot 55 \\
2.59 \\
2 \cdot 48 \\
2.93 \\
2.87 \\
2.96\end{array}$ & $\begin{array}{c}14 \\
7 \\
9 \\
8 \\
13 \\
1 \\
2= \\
2= \\
5 \\
6 \\
4 \\
11 \\
10 \\
12\end{array}$ & $\begin{array}{l}20 \cdot 7 \\
17.9 \\
21.4 \\
15 \cdot 7 \\
20.5 \\
21.4 \\
19.2 \\
15 \cdot 8 \\
19 \cdot 7 \\
15.4 \\
17.2 \\
21.7 \\
17.1 \\
18.8\end{array}$ & $\begin{array}{c}11 \\
6 \\
12= \\
2 \\
10 \\
12= \\
8 \\
3 \\
9 \\
1 \\
5 \\
14 \\
4 \\
7\end{array}$ & $\begin{array}{l}4 \cdot 0 \\
3 \cdot 8 \\
4 \cdot 0 \\
3 \cdot 6 \\
3 \cdot 0 \\
3 \cdot 2 \\
2 \cdot 8 \\
2 \cdot 7 \\
3 \cdot 0 \\
3 \cdot 6 \\
2 \cdot 6 \\
4 \cdot 2 \\
4 \cdot 6 \\
3 \cdot 6\end{array}$ & $\begin{array}{c}10= \\
9 \\
10= \\
7 \\
3= \\
5 \\
2 \\
1 \\
3= \\
7= \\
13= \\
12 \\
13= \\
7\end{array}$ & $\begin{array}{l}4 \cdot 7 \\
4 \cdot 1 \\
4 \cdot 2 \\
3 \cdot 6 \\
3 \cdot 9 \\
3 \cdot 6 \\
3 \cdot 2 \\
3 \cdot 2 \\
3 \cdot 6 \\
3 \cdot 5 \\
2 \cdot 6 \\
4 \cdot 2 \\
3 \cdot 9 \\
3 \cdot 8\end{array}$ & $\begin{array}{c}14 \\
11 \\
12= \\
5= \\
9= \\
5= \\
2= \\
2= \\
5= \\
4 \\
1 \\
12= \\
9= \\
8\end{array}$ & $\begin{array}{l}9 \cdot 0 \\
8 \cdot 2 \\
8 \cdot 6 \\
5 \cdot 8 \\
7 \cdot 9 \\
5 \cdot 5 \\
6 \cdot 4 \\
7 \cdot 5 \\
6.5 \\
6 \cdot 4 \\
5 \cdot 3 \\
8 \cdot 4 \\
8.1 \\
6.7\end{array}$ & $\begin{array}{c}14 \\
11 \\
13 \\
3 \\
9 \\
2 \\
4= \\
8 \\
6 \\
4= \\
1 \\
12 \\
10 \\
7\end{array}$ & $\begin{array}{l}0 \cdot 3 \\
0 \cdot 4 \\
0 \cdot 6 \\
0 \cdot 6 \\
0 \cdot 6 \\
0 \cdot 3 \\
0 \cdot 5 \\
0 \cdot 1 \\
0 \cdot 1 \\
0 \cdot 3 \\
0 \cdot 2 \\
0 \cdot 8 \\
0 \cdot 2 \\
0.5\end{array}$ & $\begin{array}{r}6 \\
8 \\
11 \\
13 \\
12 \\
5 \\
10 \\
1 \\
2 \\
7 \\
3 \\
14 \\
4 \\
9\end{array}$ \\
\hline
\end{tabular}
Table III Physical measurements and general self reported health variables from Health and Lifestyle Survey by regional health authority (adjusted to
males aged 18 to 24 years) and regional rankings ${ }^{\mathrm{a}}$

\begin{tabular}{|c|c|c|c|c|c|c|c|c|c|c|c|c|c|}
\hline \multirow[b]{2}{*}{$\begin{array}{l}\text { Region } \\
\text { Northern } \\
\text { Yorkshire } \\
\text { Trent } \\
\text { E Anglia } \\
\text { NW Thames } \\
\text { NE Thames } \\
\text { SE Thames } \\
\text { SW Thames } \\
\text { Wessex } \\
\text { Oxford } \\
\text { South Western } \\
\text { W Midlands } \\
\text { Mersey } \\
\text { North Western }\end{array}$} & \multirow{2}{*}{$\begin{array}{l}\text { Self assessed } \\
\text { health } \\
\text { (rank) } \\
13= \\
11 \\
7 \\
5 \\
6 \\
1 \\
10 \\
3 \\
2 \\
4 \\
8= \\
13= \\
8= \\
12\end{array}$} & \multirow{2}{*}{$\begin{array}{l}\text { Number of } \\
\text { symptoms } \\
\text { in previous } \\
\text { month } \\
\text { (rank) }\end{array}$} & $\begin{array}{l}\begin{array}{l}\text { Longstanding } \\
\text { illness/ } \\
\text { disability/ } \\
\text { infirmity } \\
\text { (rank) }\end{array} \\
\begin{array}{l}11 \\
6\end{array}\end{array}$ & \multicolumn{2}{|c|}{$\begin{array}{l}F E V_{1} \\
\text { (at height } \\
1.78 m \text { ) }\end{array}$} & \multicolumn{2}{|c|}{$\begin{array}{l}\text { BMI } \\
\text { (geometric } \\
\text { mean) }\end{array}$} & \multicolumn{2}{|c|}{$\begin{array}{l}\text { Systolic blood } \\
\text { pressure } \\
\text { (geometric } \\
\text { mean) }\end{array}$} & \multicolumn{2}{|c|}{$\begin{array}{l}\text { Diastolic blood } \\
\text { pressure } \\
\text { (geometric } \\
\text { mean) }\end{array}$} & \multicolumn{2}{|c|}{$\begin{array}{l}\text { Mean arterial } \\
\text { pressure } \\
\text { (geometric } \\
\text { mean) }\end{array}$} \\
\hline & & & $\begin{array}{c}11 \\
6 \\
12= \\
2 \\
10 \\
12= \\
8 \\
3 \\
9 \\
1 \\
5 \\
14 \\
4 \\
7\end{array}$ & $\begin{array}{l}3.91 \\
4.01 \\
4.00 \\
4 \cdot 11 \\
4.01 \\
3.95 \\
3.76 \\
4.02 \\
4.08 \\
4.00 \\
3.89 \\
3.98 \\
3.78 \\
3.89\end{array}$ & $\begin{array}{r}11 \\
5 \\
6= \\
1 \\
4 \\
10 \\
14 \\
3 \\
2 \\
6= \\
8 \\
9 \\
13 \\
12\end{array}$ & $\begin{array}{l}22 \cdot 54 \\
22 \cdot 45 \\
22 \cdot 54 \\
22 \cdot 43 \\
21 \cdot 86 \\
22 \cdot 50 \\
21 \cdot 96 \\
21 \cdot 66 \\
22 \cdot 05 \\
22 \cdot 27 \\
22 \cdot 72 \\
22 \cdot 45 \\
22 \cdot 25 \\
22 \cdot 67\end{array}$ & $\begin{array}{r}11= \\
9 \\
11= \\
7 \\
2 \\
10 \\
3 \\
1 \\
4 \\
6 \\
14 \\
8 \\
5 \\
13\end{array}$ & $\begin{array}{l}121.04 \\
125 \cdot 39 \\
118 \cdot 66 \\
117.68 \\
119.78 \\
119.79 \\
119.56 \\
118.65 \\
119.03 \\
122.34 \\
121.52 \\
122.58 \\
123.26 \\
119.57\end{array}$ & $\begin{array}{r}9 \\
14 \\
3 \\
1 \\
7 \\
8 \\
5 \\
2 \\
4 \\
11 \\
10 \\
12 \\
13 \\
6\end{array}$ & $\begin{array}{l}70 \cdot 58 \\
73 \cdot 63 \\
69 \cdot 11 \\
68 \cdot 19 \\
69 \cdot 32 \\
69 \cdot 56 \\
69 \cdot 46 \\
68 \cdot 36 \\
69 \cdot 77 \\
71 \cdot 78 \\
70 \cdot 44 \\
71 \cdot 23 \\
71 \cdot 93 \\
69 \cdot 25\end{array}$ & $\begin{array}{r}10 \\
14 \\
3 \\
1 \\
5 \\
7 \\
6 \\
2 \\
8 \\
12 \\
9 \\
11 \\
13 \\
4\end{array}$ & $\begin{array}{l}90.94 \\
95.64 \\
89 \cdot 82 \\
89 \cdot 23 \\
91.03 \\
90 \cdot 43 \\
90 \cdot 76 \\
89 \cdot 38 \\
90 \cdot 46 \\
92 \cdot 01 \\
92 \cdot 26 \\
93.32 \\
93 \cdot 18 \\
90.81\end{array}$ & $\begin{array}{r}8 \\
14 \\
3 \\
1 \\
9 \\
4 \\
6 \\
2 \\
5 \\
10 \\
11 \\
13 \\
12 \\
7\end{array}$ \\
\hline
\end{tabular}

a 1 ="best"; 14 "worst"

$\mathrm{FEV}_{1}=$ forced expiratory volume in $1 \mathrm{~s} ; \mathrm{BMI}=$ body mass index

Table IV Selected indicators of the need for health care resources from 1981 census by regional health authority and rankings ${ }^{\mathrm{a}}$

\begin{tabular}{|c|c|c|c|c|c|c|c|c|c|c|c|c|c|c|}
\hline \multirow[b]{2}{*}{$\begin{array}{l}\text { Region } \\
\text { Northern } \\
\text { Yorkshire } \\
\text { Trent } \\
\text { E Anglia } \\
\text { NW Thames } \\
\text { NE Thames } \\
\text { SE Thames } \\
\text { SW Thames } \\
\text { Wessex } \\
\text { Oxford } \\
\text { South Western } \\
\text { W Midlands } \\
\text { Mersey } \\
\text { North Western }\end{array}$} & \multicolumn{2}{|c|}{$\begin{array}{l}\text { All cause, } \\
\text { all age } \\
\text { SMR } \\
1984 / 85\end{array}$} & \multicolumn{2}{|c|}{$\begin{array}{l}\text { Permanent } \\
\text { sickness } \\
(\%)\end{array}$} & \multicolumn{2}{|c|}{$\begin{array}{l}\text { Temporary } \\
\text { sickness } \\
\left(\begin{array}{l}o \\
0\end{array}\right)\end{array}$} & \multicolumn{2}{|c|}{$\begin{array}{l}\text { Social } \\
\text { classes } \\
I V \text { and } V \\
(\%)\end{array}$} & \multicolumn{2}{|c|}{$\begin{array}{l}\text { Farman } 8 \\
\text { Underpriviledged } \\
\text { area score }\end{array}$} & \multicolumn{2}{|c|}{$\begin{array}{l}\text { Townsend } \\
\text { index of } \\
\text { deprivation }\end{array}$} & \multicolumn{2}{|l|}{$\begin{array}{l}\text { DoE } \\
\text { social } \\
\text { index }\end{array}$} \\
\hline & $\begin{array}{r}113.3 \\
105.6 \\
102.6 \\
92 \cdot 2 \\
92 \cdot 4 \\
96 \cdot 3 \\
96 \cdot 1 \\
92 \cdot 1 \\
90 \cdot 7 \\
92 \cdot 7 \\
92 \cdot 5 \\
105.0 \\
109.4 \\
112.9\end{array}$ & $\begin{array}{r}14 \\
11 \\
9 \\
3 \\
4 \\
8 \\
7 \\
2 \\
1 \\
6 \\
5 \\
10 \\
12 \\
13\end{array}$ & $\begin{array}{l}2.53 \\
1.89 \\
1.85 \\
1.33 \\
1.21 \\
1.52 \\
1.53 \\
1.19 \\
1.43 \\
1.10 \\
1.70 \\
1.70 \\
2.13 \\
2.22\end{array}$ & $\begin{array}{r}14 \\
11 \\
10 \\
4 \\
3 \\
6 \\
7 \\
2 \\
5 \\
1 \\
9 \\
8 \\
12 \\
13\end{array}$ & $\begin{array}{l}0.81 \\
0.52 \\
0.53 \\
0.39 \\
0.46 \\
0.56 \\
0.46 \\
0.35 \\
0.37 \\
0.33 \\
0.41 \\
0.61 \\
0.74 \\
0.77\end{array}$ & $\begin{array}{r}14 \\
8 \\
9 \\
4 \\
7 \\
10 \\
6 \\
2 \\
3 \\
1 \\
5 \\
11 \\
12 \\
13\end{array}$ & $\begin{array}{l}25 \cdot 19 \\
23 \cdot 44 \\
23 \cdot 16 \\
22 \cdot 36 \\
17 \cdot 46 \\
21 \cdot 70 \\
19 \cdot 91 \\
14 \cdot 50 \\
20 \cdot 26 \\
18 \cdot 17 \\
20 \cdot 02 \\
23 \cdot 69 \\
25 \cdot 43 \\
24 \cdot 43\end{array}$ & $\begin{array}{r}13 \\
10 \\
9 \\
8 \\
2 \\
7 \\
4 \\
1 \\
6 \\
3 \\
5 \\
11 \\
14 \\
12\end{array}$ & $\begin{array}{r}10.89 \\
11.75 \\
5.98 \\
2.89 \\
9.41 \\
13.47 \\
11.35 \\
2.93 \\
2.96 \\
2.38 \\
2.81 \\
9.84 \\
9.71 \\
14.25\end{array}$ & $\begin{array}{r}10 \\
12 \\
6 \\
3 \\
7 \\
13 \\
11 \\
4 \\
5 \\
1 \\
2 \\
9 \\
9 \\
14 \\
\end{array}$ & $\begin{array}{r}1.43 \\
0.01 \\
-0.41 \\
-2.05 \\
-0.34 \\
0.46 \\
-0.47 \\
-2.36 \\
-2.11 \\
-2.07 \\
-1.93 \\
0.26 \\
0.80 \\
0.33\end{array}$ & $\begin{array}{r}14 \\
9 \\
7 \\
4 \\
8 \\
8 \\
12 \\
6 \\
1 \\
2 \\
3 \\
5 \\
10 \\
13 \\
11\end{array}$ & $\begin{array}{l}2.73 \\
2.81 \\
1.85 \\
0.02 \\
2.55 \\
3.61 \\
2.96 \\
0.65 \\
0.29 \\
0.09 \\
0.78 \\
3.22 \\
3.15 \\
3.94\end{array}$ & $\begin{array}{r}8 \\
9 \\
6 \\
1 \\
7 \\
13 \\
10 \\
4 \\
3 \\
2 \\
5 \\
12 \\
11 \\
14\end{array}$ \\
\hline
\end{tabular}


Table $V$ Productmoment correlation matrix of health variables from Health and Lifestyle Survey and selected need indicators at regional health authority level

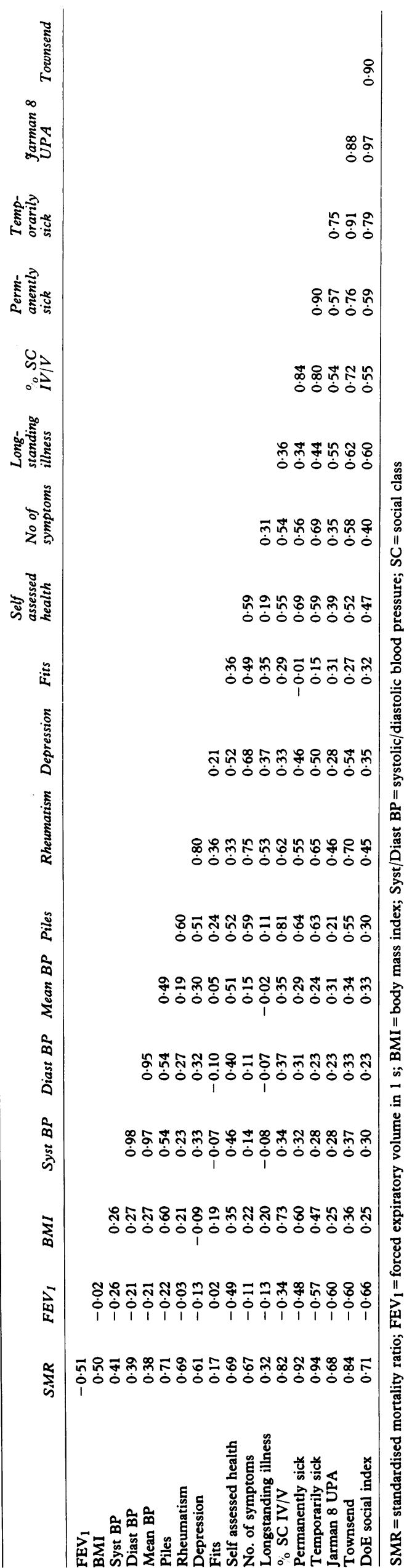

reported rheumatic disorders $(r=0.75)$, followed by self reported depression $(r=0.68)$ and self assessed health $(r=0.59)$. Longstanding illness, disability, or infirmity was most highly correlated with rheumatic disorders $(r=0.53)$.

Of the physical measures, $\mathrm{FEV}_{1}$ was most highly correlated with self assessed health $(r=0.49)$ and body mass index with piles $(r=0 \cdot 60)$. Systolic, diastolic, and mean arterial blood pressure were most highly correlated with piles $(r=0.54,0.54$, and 0.49 , respectively).

CORRELATION OF HEALTH VARIABLES FROM THE HEALTH AND LIFESTYLE SURVEY AND ROUTINELY AVAILABLE "NEED" INDICATORS

Self assessed health was most strongly correlated at regional level with all cause standardised mortality ratio $(r=0.69)$, followed by permanent sickness $(r=0.69)$ (table $V)$. Number of symptoms was most highly associated with temporary sickness $(r=0.69)$, followed by standardised mortality ratio $(r=0.67)$. Longstanding illness was most highly correlated with the Townsend index $(r=0.62)$ and the DoE social index $(r=0.60)$.

Standardised mortality ratio, which is currently used in the RAWP formula for allocation of funds from the Department of Health to regional health authorities, showed a reasonable correlation with the majority of the self reported variables and physical measures in the Health and Lifestyle Survey (table IV). It was most strongly associated with self assessed health $(r=0.69)$, number of symptoms $(r=0.67)$, and self reported rheumatism $(r=0.69)$, but only weakly correlated with longstanding illness $(r=0 \cdot 32)$. Standardised mortality ratio was correlated with all the other need indicators such as temporary sickness $(r=0.94)$ and Jarman UPA score $(r=0.68)$.

REGRESSION OF SELECTED NEED INDICATORS ON HEALTH VARIABLES FROM THE HEALTH AND LIFESTYLE SURVEY

It was not possible to regress each potential overall measure of health or deprivation on all the individual measures of health from the Health and Lifestyle Survey because there were more variables $(n=18)$ than regions $(n=14)$. Instead, upwards stepwise regression was used to try to assess which variables were related to one another (table VI). Stepwise regression on the 12 health variables from the Health and Lifestyle Survey revealed that the standardised mortality ratio was related to rheumatic disorders and to $F V_{1}$ negatively, and to body mass index positively. Self assessed health was related positively to self reported rheumatic disorders and negatively to $\mathrm{FEV}_{1}$. Turning to the other routinely available "need" indicators, permanent sickness was related to self assessed health and to body mass index; and temporary sickness was related to number of symptoms in the last month and to body mass index, and negatively to $\mathrm{FEV}_{1}$. The proportion of the population in social classes IV and $\mathrm{V}$ was related to self reported piles. After stepwise regression, the Jarman 8 UPA score was found to be related negatively to $F E V_{1}$ and positively to longstanding illness, disability, or infirmity; the Townsend index was related positively to rheumatic disorders and negatively 
to $\mathrm{FEV}_{1}$; and the DoE social index was related positively to longstanding illness and negatively to $\mathrm{FEV}_{1}$.

\section{Discussion}

The results from the analysis of data at regional health authority level should be interpreted with care. With only 14 regions and a considerable number of health variables, there is a likelihood of finding associations by chance, with no means of detecting which relationships are genuine. It was not sensible to analyse the Health and Lifestyle Survey data at district health authority level because the resulting sample sizes would have been too small to be meaningful.

\section{VARIATIONS IN PREVALENCE OF CONDITIONS}

The first noteworthy feature of the results is the lack of a statistically significant interregional variation in the prevalence of a number of the self reported conditions such as chronic bronchitis, "heart trouble", and high blood pressure which are well known from epidemiological studies to show marked regional variations in prevalence and mortality. ${ }^{22-25}$ However, the discrepancy between the results of the Health and Lifestyle social survey and epidemiological studies may be more apparent than real. Firstly, those with the most serious manifestations of disease are automatically excluded from a household survey and this may affect the relative prevalence between regions. Secondly, the regional distribution of these conditions (eg, heart disease and bronchitis) in the Health and Lifestyle Survey does appear to match the available evidence in that rates are higher in Wales, the north, and the midlands than in the south (see Cox et al, ${ }^{19} \mathrm{fig} 2.1, \mathrm{p} 8$ ). However, the variation in the rates when analysed by NHS region did not reach statistical significance. In comparison to variation in mortality, particularly from heart disease, this could be due to lack of power of the Health and Lifestyle Survey data to detect comparable differences. Thirdly, the evidence of marked regional variations in blood pressure from the British Regional Heart Study (BRHS) and subsequent Nine Towns study is for single towns whereas the Health and Lifestyle Survey data are for whole regions. The range of $7.7 \mathrm{~mm} \mathrm{Hg}$ for systolic blood pressure and $5.4 \mathrm{~mm} \mathrm{Hg}$ for diastolic blood pressure between regions in the Health and Lifestyle Survey (table III) is less than that between the BRHS Nine Towns, ${ }^{26}$ but the fact that the sample size of the Health and Lifestyle Survey was nearly two and a half times that of the Nine Towns study compensates for this. However, it is evident from table III that the range is due mainly to high means in Yorkshire. Excluding Yorkshire, the systolic and diastolic ranges are $5.6 \mathrm{~mm} \mathrm{Hg}$ and $3.7 \mathrm{~mm} \mathrm{Hg}$, respectively, with little difference in means between the majority of the regions. Finally, Health and Lifestyle Survey data for males and females have been combined in the current study. The survey pattern for hypertension in males $^{19}$ is consistent with the BRHS ${ }^{24}$ and the subsequent Nine Towns study, ${ }^{26}$ the lowest prevalence being in the south and east and the highest in the north and north west. For women, the Health and Lifestyle Survey results are not consistent, the highest prevalence of female hypertension being in the south east.

REGIONAL RANKINGS ON HEALTH AND SOCIOECONOMIC VARIABLES

The health variables from the Health and Lifestyle Survey which differed significantly between regions do not give generally consistent regional rankings (tables II and III). Not surprisingly, the physiological and physical measurements of $\mathrm{FEV}_{1}$, body mass index, and blood pressure, which reflect very different aspects of bodily functioning regarded as prognostic of different types of disease, provide inconsistent rankings for most regions. For example, South East Thames performs worst of all on respiratory function $\left(\mathrm{FEV}_{1}\right)$, but is ranked as high as third on obesity as measured by body mass index (see table III). The self reported and self assessed variables from the Health and Lifestyle Survey also show inconsistent regional rankings. The disparity in rankings between self assessed health and longstanding illness, disability, or infirmity is particularly noteworthy. At the extreme, North East Thames has the best self assessed health, but ranks twelfth on longstanding illness. The "need" indicators based on routine data generally show a higher degree of consistency in their regional rankings than the Health and Lifestyle Survey variables, though again there are notable exceptions (table IV). Part of the inconsistency in the ranking of the self reported and self assessed Health and Lifestyle Survey variables which particularly affects London and the Thames regions may be due to the sampling method used for the original survey, which was based on standard regions, not regional health authorities. It is possible that the Health and Lifestyle Survey respondents by regional health authority are not entirely representative of the health authority
Table VI Linear regression equations resulting from upwards stepwise regression of stepewise regression of
selected health and need indicators (including self assessed health) on objective and subjective health variables from Health and Lifestyle Survey, at regional health Survey, at regiona
authority level

\begin{tabular}{|c|c|c|c|c|c|c|c|c|}
\hline \multirow[b]{2}{*}{$\begin{array}{l}\text { Independent } \\
\text { Variables } \\
\end{array}$} & \multicolumn{8}{|c|}{ Dependent variables } \\
\hline & $S M R$ & $\begin{array}{l}\text { Self assessed } \\
\text { health } \\
\text { (o o fair or } \\
\text { poor) }\end{array}$ & $\begin{array}{l}\text { Permanent } \\
\text { sickness } \\
(\%)\end{array}$ & $\begin{array}{l}\text { Temporary } \\
\text { sickness } \\
(\%)\end{array}$ & $\begin{array}{l}S C \\
I V / V \\
(\%) \\
\end{array}$ & $\begin{array}{l}\text { Jarman } 8 \\
\text { UPA }\end{array}$ & Townsend & $\begin{array}{l}\text { DoE } \\
\text { social } \\
\text { index }\end{array}$ \\
\hline $\begin{array}{l}\text { Constant term } \\
\text { Rheumatic disorders (\%) }\end{array}$ & $\underset{9 \cdot 6}{11 \cdot 27}$ & $\underset{9 \cdot 2}{68.95}$ & $-12 \cdot 26$ & $-1 \cdot 19$ & $0 \cdot 18$ & $82 \cdot 35$ & $\begin{array}{r}21.56 \\
1.66\end{array}$ & $28 \cdot 16$ \\
\hline $\begin{array}{l}\text { FEV } 1 \text { (litres) } \\
\text { BMI (kg/m }) \\
\text { No of symptoms }\end{array}$ & $\begin{array}{r}-41 \cdot 0 \\
9 \cdot 4\end{array}$ & $-16 \cdot 4$ & 0.54 & $\begin{array}{r}-0.80 \\
0.17 \\
0.39\end{array}$ & & -23.9 & $-7 \cdot 40$ & $-8 \cdot 40$ \\
\hline $\begin{array}{l}\text { Piles }(\%) \\
\text { Self assessed health } \\
\text { (\% fair or poor) }\end{array}$ & & NI & 0.06 & & 0.036 & & & \\
\hline Longstanding illness (\%) & & & & & & 0.95 & & 0.32 \\
\hline$\%$ Variation explained & $84 \cdot 5$ & 53.0 & $62 \cdot 2$ & $82 \cdot 2$ & $27 \cdot 5$ & $59 \cdot 3$ & $82 \cdot 5$ & $70 \cdot 5$ \\
\hline
\end{tabular}


populations. This will depend on the sampling points used in the original fieldwork. In addition, as always in national surveys, response rates were much poorer in London than elsewhere, so the results are least secure for secondary analysis involving the four Thames regional health authorities. The interview response rate by standard region varied from $64.2 \%$ in Greater London to $79.6 \%$ in the Northern Region (mean $72 \cdot 4 \%$ ). The response rates for the physiological measurements by standard region varied from $51.0 \%$ in Greater London to $66.7 \%$ in East Anglia (mean $60.0 \%$ ). It would be surprising if nonresponse was evenly distributed across different age, sex, ethnic, and social class groups.

The disparate regional rankings of self assessed health and longstanding illness also suggest that they are elucidating different dimensions of the concept of ill health. In addition, it is apparent from the Health and Lifestyle Survey that the social determinants of both measures of health are complex (see below for a discussion of self reported longstanding illness). Different aspects of health such as physical fitness, presence of disease, and psychological health tend to be salient for different age and social groups in assessing their health as good or bad and this may affect the regional rankings.

CANDIDATE HEALTH VARIABLES FOR INCLUSION IN THE RESOURCE ALLOCATION FORMULA

The results from the correlations between the health variables from the Health and Lifestyle Survey and the routine indicators of need (table V) and the regression analysis (table VI) suggest that self assessed health is related to a wide range of health and socioeconomic variables which could be relevant to the geographic allocation of health care resources, including physical and physiological measures of health. The one exception is the relatively poor correlation of self assessed health with longstanding illness $(r=0 \cdot 19)$. Thus self assessed health may be a candidate for inclusion as an acute morbidity measure in regular health surveys and in NHS resource allocation methods, but not as a measure of chronic conditions. Of the so called "objective" physical measurements, $\mathrm{FEV}_{1}$ appears to be associated with most of the other 17 variables tested (table V), yet it is probably the most difficult and expensive of the three to collect in surveys. FEV $\mathrm{F}_{1}$ had the lowest response rate of the health variables from the Health and Lifestyle Survey. Both $\mathrm{FEV}_{1}$ and self assessed health show a moderate degree of association with all cause standardised mortality ratio at regional level ( $r=0.51$ and 0.69 , respectively). This suggests that standardised mortality ratio, which is currently used in NHS resource allocation formulas, may be a reasonable proxy for both objective and subjective definitions of ill health. Standardised mortality ratio is also well correlated at regional health authority level with the three deprivation indices included in the analysis $(r=0.68$ to 0.84$)$. These results correspond closely with the correlation between standardised mortality ratio $0-64$ years and a measure of deprivation based on overcrowding, male unemployment, low social class, and lack of a car at small area level in England, Wales, and Scotland in a recent study $(r=0 \cdot 75) .{ }^{27}$
However, like self assessed health, standardised mortality ratio is poorly correlated with longstanding illness at the regional level $(r=0 \cdot 32)$. This may indicate a case for including an additional allowance for chronic conditions in any resource allocation method based primarily on the use of mortality data as the principal indicator of morbidity. The longstanding illness, disability, or infirmity variable was not strongly associated with any of the other subjective or objective health measures of the Health and Lifestyle Survey at regional health authority level. On the other hand, longstanding illness did seem to show an association with social deprivation as measured by the DoE social index $(r=0.60)$ and the Townsend index $(r=0.62)$. In the regression analysis, both Jarman 8 UPA score and DoE social index were found to be related to $\mathrm{FEV}_{1}$ and longstanding illness. Thus there is a possible case for including a measure of deprivation in the resource allocation formula as a proxy for longstanding illness if survey data on self reported longstanding illness are not available.

The finding that standardised mortality ratios were not highly correlated with the level of self reported longstanding illness $(r=0.32)$ is surprising in view of their strong correlation with the census measure of permanent sickness $(r=0.92)$. Palmer argued in 1978 that in theory mortality should be particularly inappropriate as a morbidity indicator in the case of chronic diseases which would be expected to lead to a high use of health services but relatively few deaths. ${ }^{11}$ Yet up to now empirical studies which have used what little routinely available data exist on non-acute sickness (eg, census permanent sickness rates) have generally failed to support this criticism of the use of standardised mortality ratios and have shown a close correlation of permanent sickness with mortality rates. ${ }^{11} 141518$ The measure of permanent sickness from the census, used in most studies of mortality and morbidity, defines chronic morbidity as "permanently sick and therefore not seeking employment". It therefore applies only to the adult population of working age and identifies a particular segment of the chronically ill whose condition prevents them from working. It is highly likely to be influenced by the occupational profile of different parts of the country and applies to a small proportion of the population potentially at risk of chronic ill health. For these reasons, it has been criticised as an inadequate measure of the health service resource needs associated with the full burden of chronic disease in an area. By contrast, the measure of self reported longstanding illness, disability, or infirmity in the Health and Lifestyle Survey refers to a broader category of chronic conditions causing moderate or severe disability not specifically relating to participation in paid work. It includes chronic illness among elderly people who have retired in the normal way as well as among younger people of working age whose conditions have not prevented them from continuing to work. It is difficult to judge which of the two measures represents the more severe definition of ill health and which is likely to relate more closely to chronic ill health requiring formal health service intervention, although it is probable that the census permanent sickness 
variable isolates a smaller and more severely disabled group than the Health and Lifestyle Survey measure. On the other hand, it excludes the elderly, who are major users of services.

Self reports of "any longstanding illness, disability or infirmity" could be regarded as problematic indicators of clinical need. This may account, in part, for the lack of association between self reported longstanding illness and standardised mortality ratio. However, in comparisons, a high degree of agreement has been found between self reports of health and doctors' assessments. ${ }^{28}$ Nonetheless, it is generally accepted that the level and kind of disease reported do differ between social groups. ${ }^{19}$ This is shown in the annual General Household Survey. ${ }^{29}$ There are clear differences between age, income, education, and social class groups in what is regarded as a disease and whether it should be disclosed in a survey. ${ }^{28}$ There is evidence from the Health and Lifestyle Survey, derived from comparing the notes made by nurse assessors of obvious conditions and disabilities with the self declared prevalences, that those in higher social groups were more likely to declare less serious conditions and were more likely to declare psychiatric illnesses which were not declared by others, even when they were under treatment. ${ }^{30}$ Respondents from lower social groups tended to declare chronic conditions more readily if they were limiting. Elderly patients tended to ignore conditions such as hypertension which they regarded as normal for their age group. ${ }^{30}$

If an indicator of the prevalence of chronic ill health were to be added to the NHS resource allocation formula in England, this would present relatively few problems in the process of allocation from the Department of Health to the 14 regions, since in addition to the Health and Lifestyle Survey data, which will become increasingly dated, a similar variable is available annually from the General Household Survey, which is based on a similar size of sample to the Health and Lifestyle Survey and is therefore able to provide adequate regional samples. ${ }^{29}$ The measure of longstanding illness in the General Household Survey suffers from the same drawbacks as the Health and Lifestyle Survey variable described above. However, there are no measures of chronic ill health available for use in subregional resource allocation formulas. Hence there is interest in proxies such as a variety of deprivation indices which use data from the census. ${ }^{21}$ In the current study it was noteworthy that longstanding illness was more highly correlated with the three composite deprivation scores than with either standardised mortality ratio or any of the other Health and Lifestyle Survey morbidity variables (table V). The most obvious drawback of census based measures of deprivation is the fact that they were collected in 1981 , and that a sharp alteration in allocations will occur when 1991 census data replace 1981 data. However, they suffer from a range of other limitations ${ }^{31}$ : they are restricted to employing variables which were collected at the census, often for other purposes; data are not availabie on important topics (for example, there is no question about income or wealth); and they appear to be peculiarly sensitive to many social features of inner London which may or may not be indicators of the need for additional hospital and community health service resources. ${ }^{15}$ For example, the Jarman 8 UPA score, which was proposed for inclusion in national RAWP as an additional needs variable ${ }^{3}$ includes a residential mobility variable from the census (the proportion of the population who have changed address in the previous 12 months), yet census residential mobility was found to be negatively associated with indicators of morbidity and mortality in a previous study. ${ }^{15}$ It is likely that the census residential morbidity variable identifies a heterogeneous group of people who have moved for a wide variety of reasons, whose socioeconomic circumstances are disparate, and whose health care needs hard to generalise. The Jarman 8 UPA score also includes a variable for ethnic minorities (the proportion of the population in households headed by someone born in the New Commonwealth and Pakistan). The ethnic composition of the population may arguably affect the level of health care resource needs but there is no evidence that ethnic minority populations at present enjoy poorer health, at least not in terms of mortality. ${ }^{32}$ Thus population features such as its ethnic composition are probably best identified separately for possible inclusion in NHS resource allocation formulas to avoid "double counting", rather than as part of general indices of deprivation which include other variables that are already highly correlated with variations in health status and mortality.

For these and other reasons, ${ }^{7}$ a direct measure of chronic ill health, such as the longstanding illness variable in the Health and Lifestyle Survey is likely to be preferable to an index of deprivation as a health status supplement to standardised mortality ratio in the new national formula for capitation based finance. ${ }^{6}$ This does not exclude the possibility of including further variables relating to specific features of social deprivation (eg, ethnic minorities, or elderly people living alone) which may affect health care needs but without being reflected in the relative degree of healthiness of a population. However, the present analysis covered the relations between different measures of health from the Health and Lifestyle Survey and a range of possible need indicators for use in resource allocation and was thus concerned with "needs" associated with variations in health status rather than additional "needs" associated exclusively with social deprivation.

Unfortunately, the sample size of the Health and Lifestyle Survey does not allow District level analyses for use in subregional resource allocation. However, the decennial census has included a specific health question for the first time in 1991. The question refers to chronic ill health and will ask whether each person has any "long term illness, health problem or handicap" which limits his or her daily activities or the work he or she can do. ${ }^{33}$ In the absence of a national health interview survey, the results from this question in the 1991 census should provide helpful chronic morbidity data for national and subregional resource allocation, at least for several years after 1991.

Despite the fact that the proposal to include a measure of chronic illness in the NHS resource 
allocation formula in addition to standardised mortality ratio follows from the analysis in this paper, it should still be treated with a degree of caution. Firstly, the prevalence of longstanding illness, disability, or infirmity in the Health and Lifestyle Survey was obtained from an open ended question without prompts and cannot be taken to be exhaustive. ${ }^{19}$ There was internal evidence from the Health and Lifestyle Survey of possible underreporting of chronic conditions by non-manual social classes. ${ }^{30} \mathrm{~A}$ recent study using additional prompts to the General Household Survey longstanding illness question indicates substantial underreporting of serious or limiting conditions in response to the original question. ${ }^{34}$ Secondly, a high rate of longstanding illness, disability, or infirmity as defined in the Health and Lifestyle Survey does not necessarily indicate a commensurately high level of need for health services or health service resources, in the absence of an agreed standard for measuring severity and the threshold for professional intervention. There is, potentially at least, the possibility that the use of the standardised mortality ratio and chronic ill health in the formula together could lead to "double counting" and overemphasise differences in relative need despite their low level of intercorrelation. This consideration raises the question of the relative contribution to the unmeasurable totality of "need" made by the variables of standardised mortality ratio and chronic illness. Our analysis has not included any attempt to provide weightings for the need variables which could be applied in a resource allocation formula. The recent RAWP review undertaken by the former NHS Management Board ${ }^{2}$ commissioned a study of the spatial relation between need proxies such as standardised mortality ratio and the utilisation of NHS resources ${ }^{3}$ with a view to producing empirically defensible weightings for the need variables in the RAWP process. As a result of this research a standardised mortality ratio weighting of 0.5 is now used in the national formula. ${ }^{6}$ Quite apart from the major technical difficulties of undertaking this sort of analysis, ${ }^{7}$ the issue still remains as to the relation between the current pattern of resource utilisation and any concept of health care need which strives to be independent of the prevailing (inefficient and ineffective) manner in which NHS resources are deployed.

\section{Conclusions}

The analyses presented in this paper have shown that the subjective, physiological, and physical health variables in the Health and Lifestyle Survey tend to produce inconsistent regional rankings. This is scarcely surprising, since they cover different dimensions of the complex phenomenon of ill health. The choice of which measure(s) to include in any resource allocation formula will thus affect the funding position of regions. Although the variables of self assessed health and $\mathrm{FEV}_{1}$ correlate reasonably well with most of the other health variables in the Health and Lifestyle Survey and with a range of potential need indicators, they also correlate at regional health authority level with the standardised mortality ratio. As a consequence, the latter can be taken to be a good all round indicator of subjective and objective ill health. However, standardised mortality ratio, self assessed health, and $\mathrm{FEV}_{1}$ were found to be only weakly associated with the measure of chronic ill health in the Health and Lifestyle Survey (longstanding illness, disability, or infirmity), suggesting that it would be appropriate to consider including a measure of longstanding illness in the NHS capitation based, national resource allocation formula. From the data in this study, it would appear that inclusion of the Health and Lifestyle Survey longstanding illness variable in the resource allocation process is likely to benefit the Thames regions and Wessex at the expense of North Western, Mersey, Northern, and Oxford regions.

We would like to thank the Health Promotion Research Trust (HPRT) for financial support in carrying out the analysis. We would also like to thank Mildred Blaxter, Walter Holland, Myfanwy Morgan, and an anonymous reviewer appointed by the HPRT who were kind enough to offer us constructive criticism.

\section{Appendix}

FORMULATION OF HEALTH VARIABLES FOR THE ANALYSIS Each health variable from the Health and Lifestyle Survey was analysed allowing for age (the conventional 10 year age bands), sex, and their interaction. Body mass index and the blood pressure variables of systolic, diastolic, and mean arterial pressure (the lowest of four measurements for each individual were used) were positively skewed and so were log transformed and the resulting regional health authority means were antilogged. Forced expiratory volume in one second $\left(\mathrm{FEV}_{1}\right)$ was chosen from the three measures of respiratory function available in the Health and Lifestyle Survey $\left(\mathrm{FEV}_{1}\right.$, forced vital capacity, and peak expiratory flow) as this index was regarded by the survey research team as less likely to have been affected by the respondents' inappropriate use of the spirometer. ${ }^{19}$ $\mathrm{FEV}_{1}$ was entered into the analysis without any transformation, but adjusted for height as well as age and sex.

In the Health and Lifestyle Survey, respondents were asked whether they had ever had a series of common diseases and disorders (asthma, chronic bronchitis, other chest trouble, diabetes, stomach or other digestive disorder, piles or haemorrhoids, liver trouble, rheumatic disorder or arthritis, heart trouble, lung cancer, other cancers, severe depression or other nervous illness, varicose veins, high blood pressure, stroke, migraine, back trouble, epilepsy or fits). Self reported illnesses, including the prevalence of any longstanding illness, disability, or infirmity, were analysed as binary outcome variables with treated and untreated illnesses being combined. Respondents' self assessed health (in relation to someone of their own age) was dichotomised into "excellent/good" or "fair/poor" for the purposes of the analysis. For each outcome variable a log-linear model was used to derive a continuous variable in the form of the age and sex adjusted proportion positive for each regional health authority.

Respondents were also asked whether they had experienced the following symptoms in the previous month: headaches; hay fever; difficulty sleeping; constipation; trouble with eyes; a bad back; nerves; colds and flu; trouble with feet; always feeling tired; kidney or bladder trouble; painful joints; difficulty concentrating; palpitations or breathlessness; trouble with ears; worry; indigestion or other stomach trouble; sinus trouble, or catarrh; persistent cough; dizziness; and trouble with periods or the menopause. The number of symptoms reported by respondents in the previous month (possible range $0-20$ ) was also analysed as a continuous variable by transformation to $\log _{10}$. The resulting regional means were antilogged. 
Means of continuous variables and proportions for binary outcome variables were thus derived for each regional health authority, adjusted to males aged 18 to 24 years.

1 Department of Health and Social Security. Sharing resources for health in England: report of the Resource Allocation for health in England: report of the
Working Party. London: HMSO, 1976.

2 Department of Health and Social Security. Review of the Department of Health and Social Security. Review of the
Resource Allocation Working Party Formula: final report by Resource Allocation Working Party Formula: final report
the NHS Management Board. London: DHSS, 1988.

3 Coopers and Lybrand, Department of Geography, Queen Mary College, London and Department of General Practice, St Mary's Hospital Medical School, London. Integrated analysis for the Review of RAWP: report. London: Coopers and Lybrand, 1988.

4 Jarman B. Identification of underprivileged areas. $B M \mathcal{F}$ 1983; 286: 705-9.

5 Secretaries of State for Health, Wales, Northern Ireland and Scotland. Working for patients. Cm 555. London: HMSO, 1989.

6 Department of Health. NHS Review Working Paper No. 2. Funding and contracts for hospital services. London: HMSO, 1989.

7 Mays N. NHS resource allocation after the 1989 White Paper: a critique of the research for the RAWP review. Community Med 1989; 11: 173-86.

8 Forster DP. Mortality, morbidity and resource allocation. Lancet 1977; i: 997-9.

9 Ferrer HP, Moore A, Stevens GC. The use of mortality data in the report of the Resource Allocation Working Party (HMSO) 1976. Public Health 1977; 91: 289-95.

10 Snaith AH. Subregional resource allocations in the National Health Service. $\mathcal{F}$ Epidemiol Community Health 1978; 32 16-21.

11 Palmer SR. The use of mortality data in resource allocation. In: Brotherston J, ed. Morbidity and its relationship to
resource allocation. Cardiff: Welsh Office, 1978: 25-39.

12 Forster DP. The relationships between health needs, socioenvironmental indices, general practitioner resources and environmental indices, general practition
utilisation. $\mathcal{F}$ Chron Dis 1979; 32: 333-7.

utilisation. $f$ Chron Dis 1979 ; 32 : $333-7$.
13 Fox PD. Managing health resources: English style. In: McLachlan G, ed. By guess or by what? Information without design in the NHS. London: Nuffield Provincial Hospitals design in the NHS.

14 Brennan ME, Clare PH. The relationship between mortality and two indicators of morbidity. $\mathcal{F}$ Epidemiol Community Health 1980; 34: 134-8.

15 Mays N, Chinn S. Relation between all cause standardised mortality ratios and two indices of deprivation at regional and district level in England. $\mathcal{F}$ Epidemiol Community Health 1989; 43: 191-9.

16 Brennan ME, Lancashire R. Association of childhood mortality with housing status and unemployment. $f$ Epidemiol Community Health 1978; 32: 20-33.
17 Carstairs V. Multiple deprivation and health state. Community Med 1981; 3: 4-13.

18 Townsend $\mathrm{P}$, Phillimore $\mathrm{P}$, Beattie A. Health and deprivation: inequality and the north. London: Croom Helm, 1988.

19 Cox BD, Blaxter M, Buckle ALJ, Fenner NP, et al. The health and lifestyle survey: preliminary report of a nationwide survey of the physical and mental health, attitudes and lifestyle of a random sample of 9,003 British adults. Cambridge: Health Promotion Research Trust, 1987 .

20 Blaxter $M$. Evidence on inequality in health from a national survey. Lancet 1987; ii: $30-3$.

21 Townsend P. Deprivation. $₹$ Social Policy 1987; 16: 125-46. 22 Office of Population Censuses and Surveys. Area mortality. Office of Population Censuses and Surveys. Area mortality. Decennial Supplement

23 Ferris BG, Holland WW, Speizer F, Tessier JF. The development of respiratory disease in adults. In: Freour P, link between theory and practice. London: Kimpton Medical link between theory and practice.

24 Shaper AG, Pocock SJ, Walker M, Cohen NM, Wale CJ, Thomson AG. British Regional Heart Study: cardiovascular risk factors in middle aged men in 24 towns. BMY 1981; 283: 179-86.

25 West $R$. Geographical variations in mortality from heart disease in England and Wales. Br $\mathcal{F}$ Prev Soc Med 1977; 31 : 245-50.

26 Bruce NG, Cook DG, Shaper AG, Thomson AG Geographical variations in blood pressure in British men and women. $\mathcal{F}$ Clin Epidemiol 1990; 43: 385-98.

27 Carstairs V, Morris R. Deprivation: explaining differences in mortality between Scotland and England and Wales. BMF 1989; 229: 886-9.

28 Blaxter $M$. Self-definition of health status and consultation rates in primary care. $Q \mathcal{F}$ Soc Affairs $1985 ; 1: 131-71$.

29 Office of Population Censuses and Surveys Social Survey Division. General Household Survey, 1987. Series GHS No 17. London: HMSO, 1989.

30 Blaxter M. Health and lifestyles. London: Tavistock Routledge, 1990.

31 Carr-Hill RA. Revising the RAWP formula: indexing deprivation and modelling demand. Discussion Paper 41 York: University of York, Centre for Health Economics, 1988 .

32 Benjamin B. Variation of mortality in the United Kingdom with special reference to immigrants and minority groups. In: Coleman DA, ed. Demography of immigrants and minority groups in the United Kingdom. London: Academic

33 Office of Population Censuses and Surveys and General Register Office (Scotland). 1991 Census: summary of the Government proposals. Census Newsletter No 6, 19 July, 1988

34 MRC Medical Sociology Unit. Work in progress, February 1990. Glasgow: MRC Medical Sociology Unit, University of Glasgow, 1990 